\title{
Síndrome de Klippel-Feil autosómico dominante: una malformación de segmentación vertebral
}

\author{
Klippel-Feil autosomal dominant syndrome: \\ a malformation of vertebral segmentation
}

\section{Víctor Hugo Guapi Nauñay ${ }^{\mathrm{a}}$, Iván Alejandro Martínez Carvajal ${ }^{\mathrm{b}}$}

aServicio de Neonatología. Asesoramiento Genético del Hospital Provincial General "Luis G. Dávila". Tulcán, Ecuador 'Radiología e Imágen del Hospital Provincial General "Luis G. Dávila". Tulcán, Ecuador

Recibido: 12 de junio de 2018; Aceptado: 2 de enero de 2019
Palabras clave: Síndrome de Klippel-Feil; anomalías congénitas; vértebras cervicales; escoliosis 


\begin{abstract}
Klippel-Feil syndrome is a highly heterogeneous complex skeletal disorder characterized by the congenital fusion of two or more cervical vertebrae. The classic clinical triad consists of a short neck, low hairline, and neck movements limitation. The associated mutations are located in the loci of the GDF3 gene (chromosome 12p13.31), GDF6 (chromosome 8q22.1), and MEOX1 (chromosome 17q21.31). Objective: To describe the clinical-radiological findings and pedigree of a patient with Klippel-Feil syndrome. Clinical case: A 5-year-old patient with short neck, low posterior hairline, and limitation of lateral movements. The cervical flexion and extension radiographs showed fusion blocks between C1-2-3, C4-5, and C6-7. The chest CT scan showed multiple hemivertebrae in the upper third of the thoracic vertebrae corresponding to ribs I-IV. The karyotype was normal, 46, XX. Reduced penetrance was present in five of the family members. The fusion of C2-3 was present in four members and one individual had low fusion in C5-6. Three of the five affected individuals had a fusion between the capitate and the hamate bone. Conclusion: The malformation of congenital vertebral segmentation is a case of interest since it is an uncommon diagnosis in the pediatric age and whose clinical suspicion can be generated from the clinical examination, radiological study complemented with the pedigree interpretation in Mendelian inheritance disorders, allowing to provide opportunely genetic counseling to the family.
\end{abstract}

\section{Keywords:}

Klippel-Feil

syndrome; congenital abnormalities; cervical vertebrae; scoliosis

\section{Introducción}

El síndrome de Klippel-Feil (KFS) OMIM\# 118100, es una displasia esquelética compleja altamente heterogéneo, caracterizado por la fusión congénita de dos o más vértebras cervicales ${ }^{1}$. Es causado por un fracaso en la segmentación normal de las vértebras durante la cuarta semana de gestación ${ }^{2}$. La triada clínica clásica consiste en cuello corto, implantación baja del cabello y limitación para los movimientos del cuello. Solo entre el 34 y $74 \%$ de los casos diagnosticados presentan las manifestaciones clínicas clásicas ${ }^{3}$. La incidencia estimada es de 1 por cada 40.000 a 42.000 nacimientos en el mundo y es más frecuente en el sexo femenino con una relación de 1,5/1 .

Existen 4 tipos de $\mathrm{KFS}^{5}$; estos son: tipo 1, clásica fusión única en C1 (autosómico recesivo); tipo 2, sinostosis de C2-3, fusión cervical, torácica, lumbar y muestra expresión variable dentro de una familia (autosómico dominante); tipo 3, fusión cervical aislada (recesiva) y tipo 4, fusión en vértebras cervicales (probablemente ligado al cromosoma X) clasificado según las diferencias de sinostosis vertebrales en regiones específicas y el patrón de herencia. En Ecuador, los cuatro casos descritos fueron de la consulta de Genética de Paz y Miño (2014a) ${ }^{6}$.

Las mutaciones asociadas al síndrome de KFS autosómico dominante ${ }^{7,8}$ se localizan en los genes GDF3, GDF6 y MEOX1. El GDF3 (es un factor de diferenciación de crecimiento 3 ) miembro de la familia TGF- $\beta /$ BMP (factor de crecimiento transformante-beta/proteína morfogenética ósea) y mutaciones en este gen causan la deformidad Klippel-Feil III. GDF6 (factor de diferenciación del crecimiento 6) es también miembro de la familia TGF- $\beta$ /BMP y mutaciones en este gen causan la deformidad de KFS I. La proteína codificada por el gen MEOX1 (proteína homeobox MOX-1) desempeña un papel en la somatogénesis y está específicamente involucrado en la formación del esclerótomo ${ }^{9,10}$.

Los genes Pax también juegan un rol importante durante la embriogénesis de los vertebrados, posiblemente al determinar la temporalidad y el lugar de formación de órganos como, cerebro, los ojos, oídos, nariz, columna vertebral, riñones y músculos de las extremidades.

Considerando su organización genómica, las secuencias de dominio y los patrones de expresión la familia de genes Pax se ha clasificado en cuatro subfamilias; la familia 1 está constituida por los genes Paxl y $\operatorname{Pax} 9$, la familia 2 por $\operatorname{Pax} 2, \operatorname{Pax} 5$ y $P a x 8$; la familia 3 por $\operatorname{Pax} 3$ y $\operatorname{Pax} 7$; y la familia 4 por los genes $\operatorname{Pax} 4$ y Pax6 $)^{11}$.

Durante la cuarta semana de desarrollo embrionario se produce la diferenciación de somitas, donde las células de la porción ventral o esclerotomo, expresan el factor de transcripción Paxl, el que inicia la cascada de genes que forman el cartílago y hueso para la formación de vértebras, costillas y esternón ${ }^{2,10}$. La vértebra en barra se produce por la insuficiente segmentación de dos o más vértebras ${ }^{12}$.

El objetivo de la presente investigación consistió en describir los hallazgos clínico-radiológicos y genealogía de una paciente con síndrome de Klippel-Feil.

\section{Caso clínico}

Paciente de sexo femenino que fue derivada a los 5 años al servicio de genética con los antecedentes de hija única de una pareja sin historia de consanguinidad 

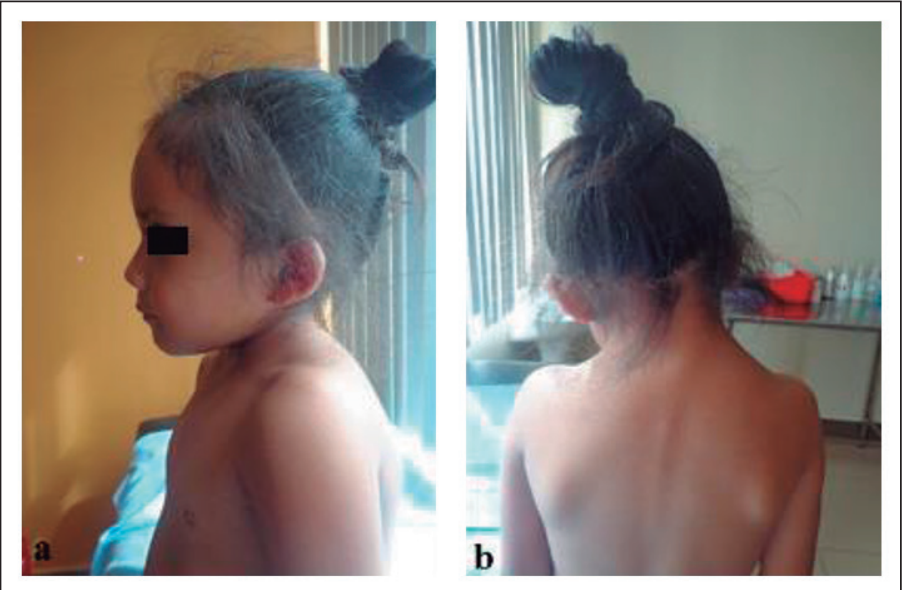

Figura 1. Vista lateral de paciente de 5 años que exhibe cuello corto (a). Vista posterior con cabello de implantación baja y deformidad de Sprengel caracterizado por escápula alada (b).

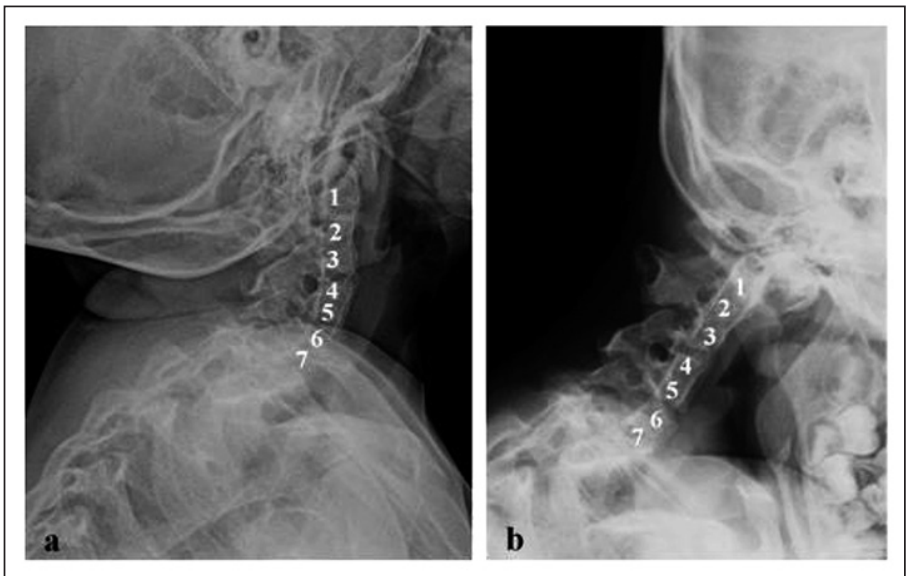

Figura 2. Las radiografías cervicales laterales (a y b) evidencian sinostosis de cuerpos vertebrales de C1-2-3, C4-5 y C6-7. a: Extensión; b: Flexión.

o endogamia; con siete controles prenatales, la madre sin antecedentes de consumo de alcohol o ácido valproico durante el embarazo; nació por parto eutócico de 38 semanas de gestación según fecha de última menstruación, con antropometría que correspondió a una recién nacida a término pequeña para la edad gestacional, con peso: $2.030 \mathrm{~g}$, talla: $39,5 \mathrm{~cm}$, perímetro cefálico: $29 \mathrm{~cm}$, Apgar: de 9 al minuto y a los cinco minutos, enviada de alta a los dos días de vida.

$\mathrm{Al}$ año de edad, fue remitida a Neuropediatría por "paresia braquial derecha", donde le realizaron tomografía axial computarizada (TAC) de cráneo que resultó normal. Presentó una progresión normal de los hitos del desarrollo, asistiendo a educación preescolar.

$\mathrm{Al}$ examen de ingreso al servicio de genética destacaba inteligencia normal. En el examen segmentario se observaba desviación de la cabeza al lado izquierdo; cráneo y cara con frente alta y amplia; hipoplasia de tercio medio de la cara; cejas ligeramente arqueadas, pestañas largas, córneas blancas; nariz: ancha achatada con ligero filtro nasal; mejillas gruesas; boca: labios levemente gruesos, regular oclusión y mala posición de piezas dentarias; retrognatia; pabellón auricular izquierdo en asa con rotación posterior y de baja implantación; cuello corto, cabello de implantación baja posterior, limitación para los movimientos de lateralización. En el tórax posterior se apreció escoliosis derecha de columna en la región dorsal y escápulas prominentes pequeñas en posición alta; el hemitórax anterior izquierdo con elevación de $2^{\text {do }}$ y $3^{\text {er }}$ cartílago costal; restricción para la flexión de codos, muñecas, manos y pies. No presentó signos clínicos de compresión medular (figura 1).

Los exámenes de laboratorio realizados reportaron: hemograma, perfil bioquímico y pruebas tiroideas en rango normal. El análisis citogenético convencional, mediante cultivo de linfocitos obtenidos de sangre periférica, con técnicas de bandas GTG y conteo de 20 metafases mostró cariotipo normal femenino 46,XX. La radiografía simple en flexión y extensión de la región cervical evidenció múltiples bloques de fusión en cuerpos vertebrales con ausencia de espacios intervertebrales entre C1-2-3, C4-5, C6-7 (figura 2). La radiografía de la muñeca exhibió fusión entre el hueso grande y ganchoso en el carpo (no mostrado).

Los hallazgos de la Tomografía Computarizada (TC) con reconstrucción volumétrica incluyeron en: hemitórax izquierdo sinostosis de los arcos costales en el extremo posterior de I-IV, este último más corto en relación con los arcos costales contiguos (figura 3 a); hemitórax derecho con sinostosis de los arcos costales I-III en el tercio medio y extremo posterior; con pobre diferenciación entre ellos, en mayor grado al contralateral (figura 3b). III arco costal corto con relación al IV y ausencia de la costilla XII (figura $3 \mathrm{c}$ ).

Además, exhibió múltiples hemivértebras no segmentadas del tercio superior de las vértebras torácicas (T1-T4) correspondientes a las costillas I-IV y vértebras en cuña de T5-T6. Marcada escoliosis derecha (figura $3 \mathrm{c}$ ).

Las evaluaciones cardiológica, oftalmológica, auditiva y la ecografía abdominal fueron normales.

Además de la evaluación clínica, se confeccionó la genealogía de la paciente, definida como caso índice III-5 (figura 4). Al interpretar la genealógia familiar, se definió que los individuos (I-5, II-6, II-10, II-14, III5) presentaban sintomatología compatible de KFS con patrón de herencia probable autosómico dominante por lo tanto, se indicó radiografía de columna cérvico torácica.

Considerando la disminución de la aptitud reproductiva y también a la baja prevalencia de estos defec- 

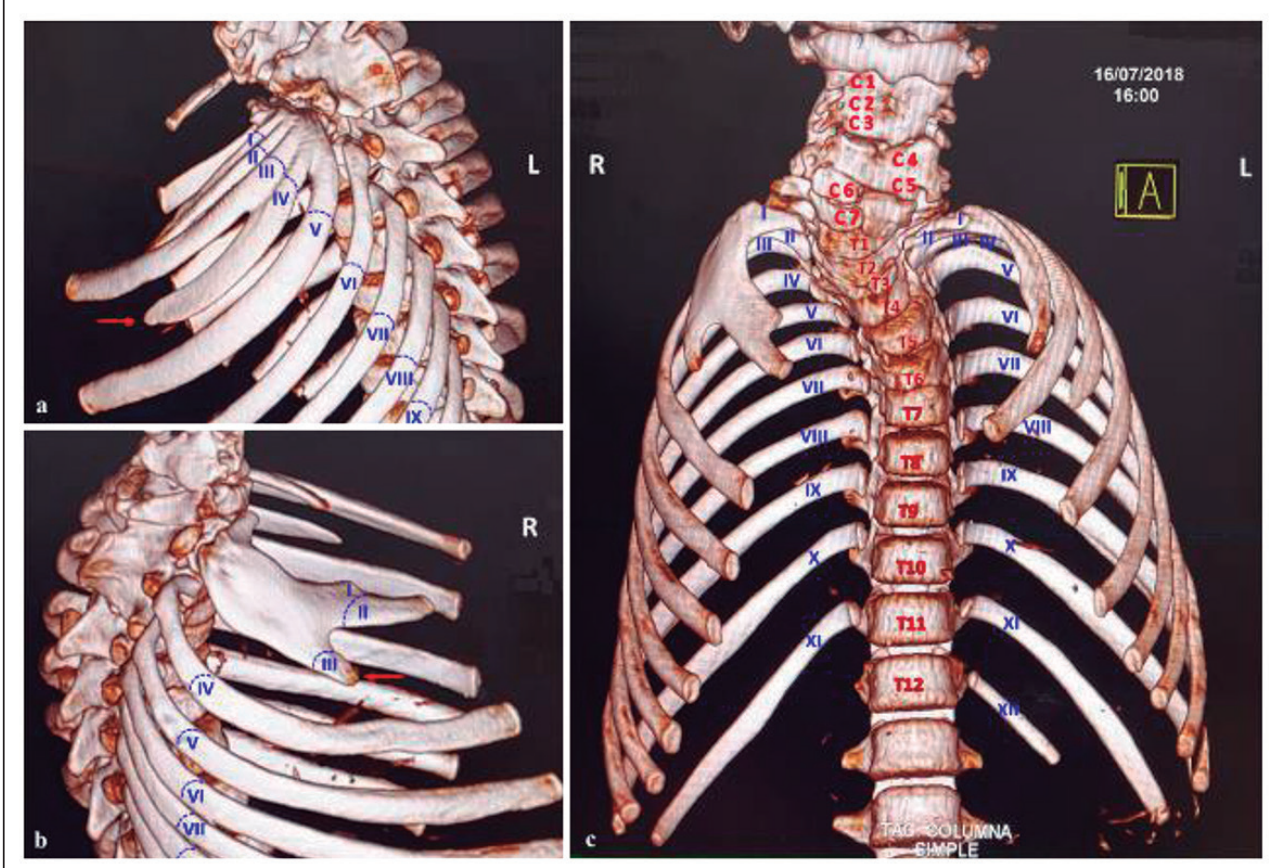

Figura 3. Reconstrucción Tomografía Computarizada 3D de tórax óseo, vista anterior con ausencia de espacio intercostal en el extremo posterior del arco costal: I al IV de hemitórax izquierdo (a) y I al III de hemitórax derecho (b) respectivamente. Acotamiento de arcos costales esternales: IV izquierdo y III derecho, con ausencia de XII costilla flotante homolateral (c). Se ha retirado electrónicamente el esternón y las clavículas.

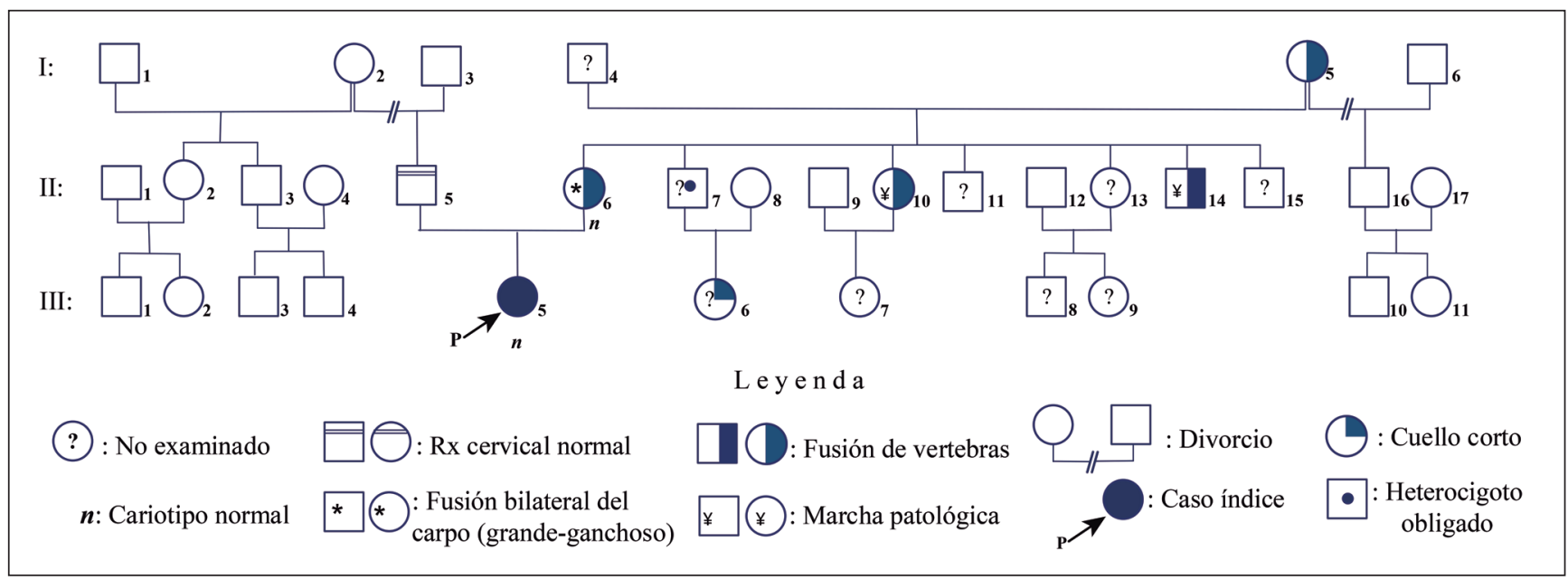

Figura 4. Genealogía de la familia con síndrome de Klippel-Feil.

tos, es poco probable que exista unión entre progenitores (II-5 y II-6) afectados por una mutación causante del mismo síndrome. Para descartar esta posibilidad se realizó radiografía de columna cérvico torácica a II-5, la cual fue normal (no mostrado).

En la radiografía de columna cervical de I-5 se evidenció fusión media de la apófisis espinosa entre C2-3 con parcial osificación entre los cuerpos vertebrales donde el espacio intervertebral es significativamente estrecho, con ausencia de fusión carpal (figura 5a).

La paciente II-6 (figura 5d) presentó fusión media de la apófisis espinosa entre C5-6 y disminución importante en el espacio intervertebral, también están fusionados los huesos del carpo (grande-ganchoso). En la ecografía abdominal se informó riñones de características normales, así como uréteres y vejiga sin alteraciones. El examen audiológico reportó ausencia de patología y el análisis citogenético convencional, con bandeo G y conteo de 20 metafases mostró un cariotipo de 46,XX.

Los pacientes II-10 y II-14, caminaban a pequeños pasos rozando el piso, porque no pueden levantar las 

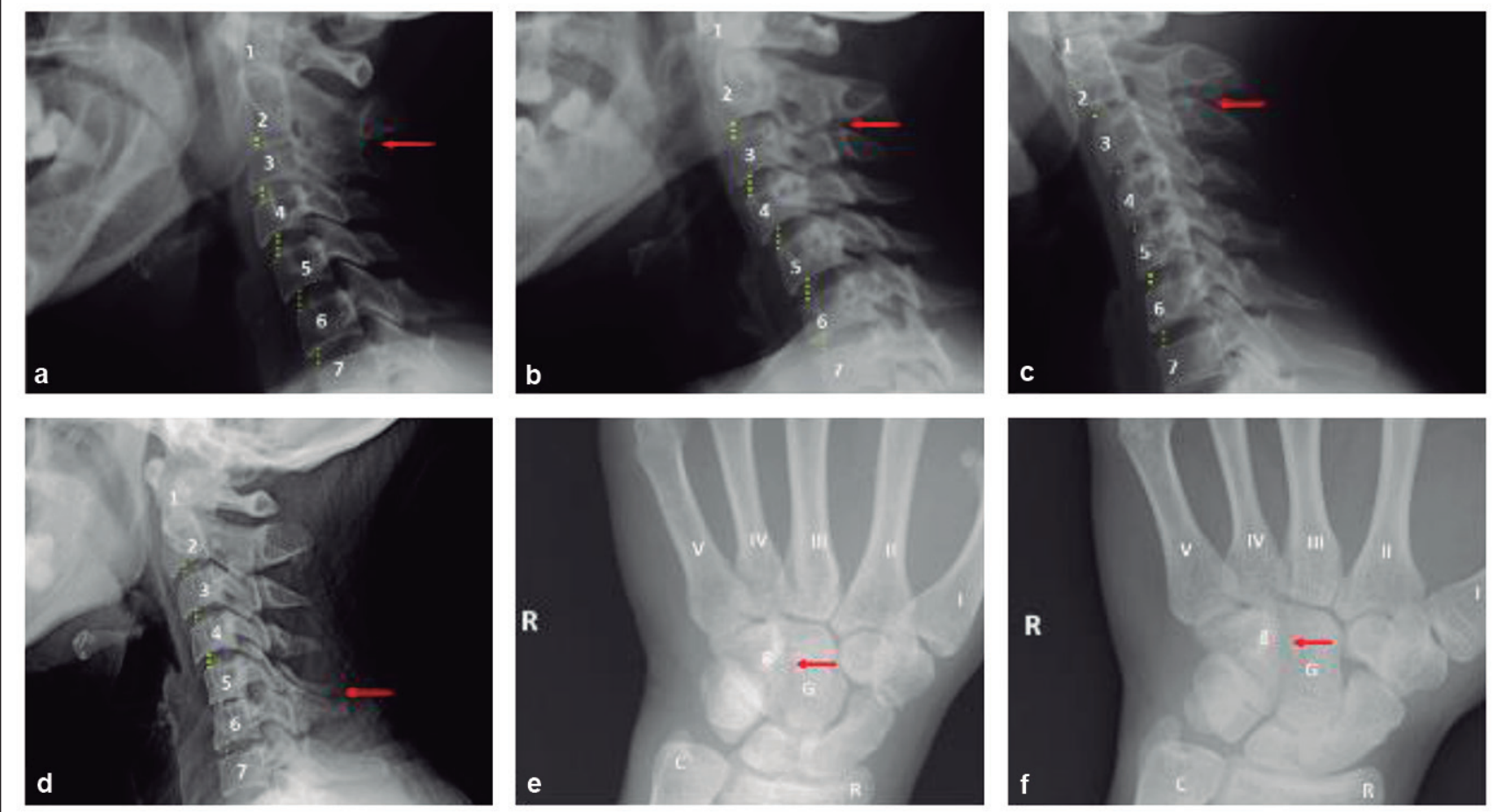

Figura 5. Radiografías de columna cervical que evidencian espacio intervertebral significativamente estrecho y fusión media de la apófisis espinosa entre: C2-3 del paciente I-5 (a), II-10 (b) y II-14 (c), respectivamente; . C5-6 del paciente II-6 (d). La radiografía de la muñeca exhibe fusión entre el hueso grande y ganchoso en el carpo: Del paciente II-10 (e) y II-14 (f), respectivamente. R: derecho; G: grande; g: ganchoso.

piernas al mantenerlas juntas de la rodilla para arriba, como consecuencia de la afectación en la vía motora piramidal. La radiografía de columna cervical identificó fusión media de las apófisis espinosas entre C2-3 y osificación parcial entre los cuerpos vertebrales, con estrechamiento significativo del espacio intervertebral (figuras 5 b y c). La radiografía de la muñeca exhibió fusión entre el hueso grande y ganchoso en el carpo (figuras 5 e y f). Reciben actualmente manejo con fisioterapia.

Los cuatro familiares maternos (I-5, II-6, II-10, II14) del caso índice (III-5) fueron examinados y evaluados, incluido II-5 (figura 4) utilizando radiografía de columna cérvico torácica y huesos del carpo, de los ocho individuos maternos vivos. Cinco de los seis evaluados exhibieron al menos estrechamiento importante del espacio intervertebral entre C2-3 o C5-6.

El KFS estaba presente en cinco miembros de la familia (I-5, II-6, II-10, II-14, III-5). Todos los individuos afectados presentaron fusión de columna cervical, cuatro (I-5, II-10, II-14, III-5) de ellos presentaron fusiones altas en C2-3 y uno (II-6), fusión baja en C5-6.

De los cinco individuos con afectación vertebral solo en tres (II-10, II-14, III-5), se constató fusión entre el hueso grande y ganchoso. Ninguno de los individuos afectados de la familia de la paciente III-5 en las tres generaciones, con esta entidad genética dominante se observó alteración vocal asociada a malformaciones de cartílago laríngeo.

El protocolo de investigación fue enviado al comité de ética para su comentario, revisión y aprobación; permitiendo el registro de datos del caso índice y sus familiares con la publicación de los resultados posteriormente.

\section{Discusión}

El síndrome de Klippel-Feil es causado por un fracaso en la segmentación de las vértebras cervicales con amplia variabilidad fenotípica, sin embargo una característica común de estos pacientes es la presencia de fusión vertebral cervical en C2-3 como hallazgo universal ${ }^{6}$.

La paciente III-5, presentó la triada clásica del KFS, con fusión de vértebras cervicales, cuello corto y línea de implantación baja del cabello en su región posterior, aunque solo el $34 \%$ de los casos presentan la triada completa, además de limitación de los movimientos de flexión de brazos. Actualmente con ausencia de signos clínicos de compresión medular, con buen pronóstico. Los padres, maestros y la misma paciente deben estar 
conscientes en evitar traumatismos, actividades físicas que puedan lesionar la médula con las devastadoras consecuencias que implicaría ${ }^{13-15}$.

Además de las diversas alteraciones vertebrales, este es el primer caso en que se describe sinostosis de arcos costales con KFS, demostrada con TC y reconstrucción volumétrica de columna cervico torácica, exhibiendo la necesidad de realizar estudios imagenológicos y citogenéticos en los pacientes con fusión vertebral.

En la paciente III-5, se presentó el mayor grado de severidad, con múltiples bloques de fusión de columna cervical (C1-2-3/C4-5/C6-7), y la radiografía de la muñeca exhibió fusión en el carpo. Todos estos defectos del desarrollo ocurren por la haploinsuficiencia (como mecanismo patológico) posiblemente en algunos de los otros genes como Paxl durante la embriogénesis, propuesto por McGaughran (2003), al describir la importancia en la posición específica de regulación de proliferación celular ${ }^{11}$.

La madre (II-6) tenía un fenotipo menos severo que el probando o que otros familiares, podría explicarse la penetrancia reducida considerando que tenga una mutación en un alelo y que el otro alelo (o una mutación en otro locus) tenga una mutación que atenúe la sinostosis de los cuerpos vertebrales por interacción entre alelos, o si fuera en otro locus un efecto epistático podría haber atenuado el fenotipo ${ }^{16,17}$.

En el KFS tipo II, con herencia autosómica dominante, se ha descrito la expresividad variable en severidad clínica ${ }^{18,19}$. En las radiografías de columna cervical de los casos descritos se observó diferencias de sinostosis en regiones específicas. Al no tener causa aparente de la marcha patológica de II-10 y II-14 se presumió relación con el KFS, estos pacientes presentan gran predisposición a padecer compresión de médula espinal por transferencia de fuerzas mecánicas a través de la columna cervical malformada ${ }^{20}$.

$\mathrm{Al}$ interpretar la genealogía familiar, se definió que los individuos (I-5, II-6, II-10, II-14, III-5) presentaban sintomatología compatible con KFS y con patrón de herencia autosómico dominante. Entre los criterios de este tipo de herencia identificados, están el fenotipo que aparece en todas las generaciones y uno de los progenitores de cada uno de los individuos afectados también presentan afectación. En un patrón de herencia autosómica dominante, los individuos afectados de ambos sexos tienen la misma probabilidad de transmitir el alelo mutado y en consecuencia también el fenotipo a sus hijos de ambos sexos; la expresión poco llamativa del transtorno puede dar lugar a excepciones aparentes a esta regla (figura 4).

Considerando las diferencias en el tiempo y la morfología de las sinostosis de los cuerpos vertebrales, las diferencias en la frecuencia de la fusión en regiones específicas, el patrón de herencia más probable es au- tosómico dominante y de acuerdo con la nueva clasificación del $\mathrm{KFS}^{6}$, se sugiere que los individuos en la familia estudiada corresponden al KFS tipo II asociado a $8 \mathrm{q} 22.1$.

En el planteamiento del diagnóstico diferencial (tabla 1) debería considerarse entre las primeras opciones, patologías cromosómicas con mayor prevalencia, como el síndrome de Turner, sin olvidar los trastornos monogénicos. El KFS, ha sido descrito como una manifestación del síndrome alcohólico fetal y un fenotipo similar se ha evidenciado ante el tratamiento materno con ácido valproico ${ }^{21}$.

La afonía que está directamente relacionada con la malformación de los cartílagos laríngeos está presente en el 35\% de los individuos, la deformidad de Sprengel caracterizada por escápulas en posición anormalmente alta en el 50\%. Las malformaciones audiológicas se presentan con mayor frecuencia en el sexo femenino con una relación M:F de 1:1,5; el deterioro neurosensorial está en menos del $30 \%$ de los casos de KFS, seguido por la sordera mixta y la de tipo conductivo ${ }^{1}$.

En el sistema esquelético, la escoliosis o cifosis se presenta en el $60 \%$, en nuestros casos correspondió al $40 \%$ en II-10, III-5 (figura 1), mientras que las malformaciones de sistema urinario con riñón en herradura en el 35\%, la asimetría facial y el cuello alado con el $20 \%$. Entre las malformaciones cardíacas, presentes en $4,2-14 \%$ pueden ocurrir severas lesiones como coartación de la aorta, sin embargo los defectos de tabique ventricular son los más frecuentes ${ }^{15,22,23}$.

Se ha demostrado que las mutaciones en los loci del gen GDF3 (cromosoma 12p13.1), GDF6 (cromosoma 8q22.1) y MEOX1 (cromosoma 17q21.31) están relacionadas con el $\mathrm{KFS}^{24-26}$. En una investigación de Ye M, et al. donde se identificó múltiples variantes de sentido erróneo en familias con KFS; al parecer representa uno de los pocos estudios que informa sobre la contribución de proteínas óseas morfogenéticas en individuos heterocigóticos con alteraciones en GDF3 y GDF6 ${ }^{10}$. Los pacientes reportados en la presente investigación no fueron sometidos a estudios moleculares, por la ausencia de secuenciadores en Ecuador.

\section{Conclusiones}

La paciente con malformación de segmentación vertebral congénita constituye un caso de interés por tratarse de un diagnóstico infrecuente en la edad pediátrica y cuya sospecha clínica puede generarse a partir de un buen examen clínico y estudio del caso índice, complementado con la interpretación de la genealogía en los trastornos de herencia mendeliana, permitiendo brindar un oportuno asesoramiento genético.

Los hallazgos clínicos descritos, pudieran dar una 
Tabla 1. Diagnóstico diferencial del síndrome de Klippel Feil

\begin{tabular}{|c|c|c|c|c|}
\hline Características & Turner & Murcs & Klippel Feil* & Wildervanck \\
\hline Herencia & Cromosómico & Esporádica & Autosómica dominante & Multifactorial \\
\hline Cuello corto & Sí & No & Sí & Sí \\
\hline Implantación baja de cabello posterior & Sí & No & Sí & Sí \\
\hline Movimientos lateralizados de cuello & Normales & Normales & Limitados & Limitados \\
\hline Talla baja & Sí & Sí & Sí & Sí \\
\hline Asimetría facial & No & Rara vez & No & No \\
\hline Parálisis del motor ocular externo & No & No & No & Sí \\
\hline Implantación de pabellones auriculares & Baja & Normal & Baja & Baja \\
\hline Sordera & No & PoSíblemente & No & Neurosensorial \\
\hline Cardiopatía & Sí & No & No & Sí \\
\hline Malformaciones renales & Sí & Sí & No & Sí \\
\hline Fusión de vértebras & No & Dorsales & Cervicales & Cervicales \\
\hline Escoliosis & Rara vez & Rara vez & Cérvico-torácico & Tóraco-lumbar \\
\hline Escápulas altas (Sprengel) & No & Sí & Sí & Sí \\
\hline Hipoplasia de músculos tenares & No & Rara vez & No & No \\
\hline Agenesia de pulgares & No & Sí & No & No \\
\hline Fusión del carpo (grande-ganchoso) & No & No & Sí & No \\
\hline Disgenesia del conducto Mülleriano & Sí & Sí & No & No \\
\hline Amenorrea & Sí & Sí & No & No \\
\hline Caracteres sexuales secundarios & Ausentes & Normales & Normales & Normales \\
\hline Nivel de LH/FSH & Disminuido & Normal & Normal & Normal \\
\hline Cariotipo & $45, \times 0$ & $46, X X$ & $46, x X$ & $46, X X$ \\
\hline
\end{tabular}

*Descripción del caso.

pauta de alta sospecha diagnóstica no siendo un obstáculo la ausencia del estudio molecular en el momento de establecer un diagnóstico; actualmente no está disponible masivamente secuenciadores moleculares, acontecimiento que enfatiza la importancia de la evaluación clínica descrita en la presente investigación.

\section{Responsabilidades Éticas}

Protección de personas y animales: Los autores declaran que los procedimientos seguidos se conformaron a las normas éticas del comité de experimentación humana responsable y de acuerdo con la Asociación Médica Mundial y la Declaración de Helsinki.
Confidencialidad de los datos: Los autores declaran que han seguido los protocolos del centro de trabajo sobre la publicación de datos de pacientes.

Derecho a la privacidad y consentimiento informado: Los autores han obtenido el consentimiento informado de los padres (tutores) de la paciente y/o sujetos referidos en el artículo. Este documento obra en poder del autor de correspondencia.

\section{Conflicto de intereses}

Los autores declaran no tener conflicto de intereses. 


\section{Referencias}

1. OMIM. Online Mendelian Inheritance in Man: https://www.omim.org/sea $\mathrm{rch} /$ ?index $=$ entry\&start $=1 \&$ limit $=$ $10 \&$ sort $=$ score + desc $\% 2 \mathrm{C}+$ prefix sort+desc\&search $=114000 /$, ultima visita 28-4-2018.

2. Valdés A, Pérez H, García R, López A. Embriología humana. La Habana; Editorial Ciencias Médicas; 2010. Cap. 8, Sistema muscular p. 103-8.

3. Jones M. Recognizable patterns of malformation. Sect. U Miscellaneous sequences. In: Lyons K, Crandall M, Del Campo M. Recognizable patterns of human malformation. 7th ed. Philadelphia: Elsevier; 2013.p. 796-830.

4. Cammarata F, Callea M, Maldonado M, Stock F, Bracho A, Herrera A, et al. Agenesia renal en el síndrome de KlippelFeil. Rev Can Pediatr. 2015;39(3):149-52.

5. Clarke R, Catalan G, Diwan A, Kearsley J. Heterogeneity in Klippel-Feil syndrome: a new classification. Pediatric Radiol. 1998;28(12):967-74.

6. Paz y Miño C, López A. Genética molecular y citogenética humana: fundamentos, aplicaciones e investigaciones en el Ecuador. Quito; Yachay EP; 2014. p. 27-8.

7. Hudgins L, Zadeh N. Spine and thoracic cage. In: Stevenson R, Hall J, Everman D, Solomon B. Human malformations and related anomalies. Oxford University Press; 3th ed. New York; 2016. p. 195-218.

8. Tassabehji M, Fang Z. M, Hilton E, McGaughran J, Zhao Z, E de Bock C, et al. Mutations in GDF6 are associated with vertebral segmentation defects in KlippelFeil syndrome. Hum Mutat. 2008;29(8): 1017-27.
9. Shapiro F, editor. Disordered and rid morphology in pudgy mice. Springer, Massachusetts; 2016. Chapter 4. p. 67 109.

10. Ye M, Berry-Wynne K, Asai-Coakwell M, Sundaresan P, Footz T, French C. Mutation of the bone morphogenetic protein GDF3 causes ocular and skeletal anomalies. Hum Mol Genet. 2010;19(2): 287-298.

11. McGaughran J, Oates A, Donnai D, Read A, Tassabehii M. Mutations in PAX1 may be associated with Klippel-Feil syndrome. Eur J Hum Genet. 2003;11:468-74.

12. Spigel D, Dormans J. Escoliosis congénita. En Kliegman R, Behrman R, Jenson H, Stanton B. Nelson Tratado de Pediatría. 19a ed. Vol. II. Elsevier, Barcelona; 2013. p. 2442-54.

13. Turnpenny P, Ellard S, editors. Emery's, Elements of Medical Genetics.15th ed. California: Elsevier; 2017. Sect. A, Chapter 9, Developmental genetics. p. 102-27.

14. Harper P, editor. Practical genetic counselling. 7th ed. United Kingdom: Hodder Arnold; 2010. Chapter 2, Genetic counselling in mendelian disorders. p. 2353 .

15. Figueroa J, Zepeda G, González A. Síndrome de Klippel-Feil: una enfermedad musculoesquelética, con malformaciones cardiovasculares asociadas. Bol Med Hosp Infant Mex. 2005;62(5):348-55.

16. Strachan T, Read A, editors. Human molecular genetics. 4th ed. Garland Science, New York; 2011. Chapter 15, Mapping genes conferring susceptibility to complex diseases.

17. Lantigua A, editor. Introducción a la Genética Médica. Editorial Ciencias Médicas; La Habana; 2011. Cap. 9,
Transmisión de simples mutaciones. p. 143-65.

18. Fedala S, Ali el Mahdi H, Aicha T, Ali Leyla A. Klippel-Feil syndrome: A case report and review of literature. IOSRJournal of Dental and Medical Sciences. 2016;15(12):65-7. Disponible en: doi 10.9790/0853-1512036567.

19. Nussbaum R, McInnes R, Willard H, editors. Thompson -Thompson, Genetics in medicine. $8^{\text {th }}$ ed. Elsevier; Philadelphia; 2016. Chapter 7, Patterns of single-gene inheritance. p. 107-32.

20. Surós A, Surós J, editores. Semiología médica y técnica exploratoria. 8va ed. Elsevier; Barcelona; 2001. Cap. 10, Neurología. p. 755-920.

21. Lachman R, Taybi H, editors. Radiology of syndromes, metabolic disorders, and skeletal dysplasias. $5^{\text {th }}$ ed. California; 2007.

22. Mahirogullari M, Ozkan H, Yildirim N, Cilli F, Gudemez E. Klippel-Feil syndrome and associated congenital abnormalities: evaluation of 23 cases. Acta Orthop Traumatol Turc. 2006;40(3):234-9.

23. Treviño G, Salazar S, Martínez H, Rivera G. Síndrome de Klippel-Feil: reporte de un caso. iMed Pub J. 2011;7(5):1-3.

24. Chacón O,Camarillo L, Pelaez H, Mendiola J, Zenteno J. Klippel-Feil syndrome associated with situs inversus: description of a new case and exclusion of GDF1, GDF3 and GDF6 as causal genes. Eur J Med Gen. 2012;55:414-7.

25. Patel M, Gupta R, Bajaj N, Tagore V. Klippel-Feil syndrome: a case report. Int J Res Med Sci. 2014;2(3):1197-9.

26. Agarwal K, Goel M, Bajpai J, Shukla S, Sachdeva N. Klippel-Feil Syndrome: A Rare Case Report. J Orthop Rep. 2014;4(3):53-5. 